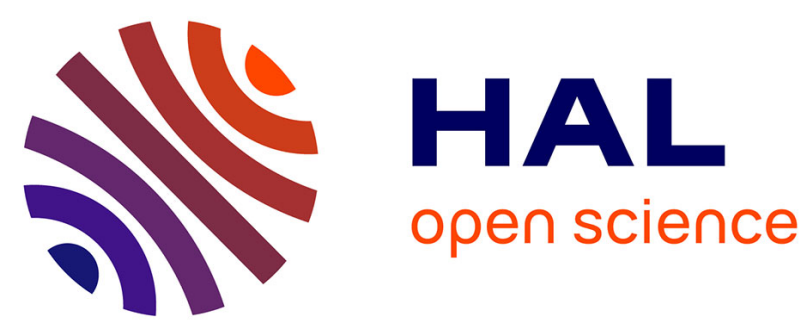

\title{
When the zebra loses its stripes but is still in the savannah: results from a semantic priming paradigm in semantic dementia.
}

Catherine Merck, Pierre-Yves Jonin, Mickaël Laisney, Hélène Vichard, Serge Belliard

\section{To cite this version:}

Catherine Merck, Pierre-Yves Jonin, Mickaël Laisney, Hélène Vichard, Serge Belliard. When the zebra loses its stripes but is still in the savannah: results from a semantic priming paradigm in semantic dementia.. Neuropsychologia, 2014, 53, pp.221-32. 10.1016/j.neuropsychologia.2013.11.024 . inserm00917649

\section{HAL Id: inserm-00917649 https://www.hal.inserm.fr/inserm-00917649}

Submitted on 12 Dec 2013

HAL is a multi-disciplinary open access archive for the deposit and dissemination of scientific research documents, whether they are published or not. The documents may come from teaching and research institutions in France or abroad, or from public or private research centers.
L'archive ouverte pluridisciplinaire HAL, est destinée au dépôt et à la diffusion de documents scientifiques de niveau recherche, publiés ou non, émanant des établissements d'enseignement et de recherche français ou étrangers, des laboratoires publics ou privés. 


\section{When the zebra loses its stripes but is still in the savannah: Results from a semantic priming paradigm in semantic dementia}

Catherine Merck a ${ }^{\text {a }}$ Pierre-Yves Jonin ${ }^{\text {a }}$, Mickaël Laisney ${ }^{\text {b,c,d,e }}$, Hélène Vichard ${ }^{\text {a }}$, Serge Belliard ${ }^{\mathrm{a}, \mathrm{b}, \mathrm{c}, \mathrm{d}}$.

\section{Affiliations}

${ }^{\text {a }}$ CHU Pontchaillou, service de neurologie, CMRR, Rennes, France.

${ }^{\mathrm{b}}$ INSERM, Unité U1077, Caen, France.

${ }^{\mathrm{c}}$ Université de Caen Basse Normandie, UMR-S1077, Caen, France.

${ }^{\mathrm{d}}$ Ecole Pratique des Hautes Etudes, UMR-S1077, Caen, France.

${ }^{\mathrm{e}}$ CHU de Caen, U1077, Caen, France.

Corresponding author

Catherine MERCK

Service de Neurologie

CMRR du CHU Pontchaillou

2 rue Henri Le Guilloux

35033 Rennes Cedex - FRANCE

Telephone: +33 2.99.28.43.21

Fax: +33 2.99.28.41.32

Email: catherine.merck@chu-rennes.fr 


\section{Abstract}

Studies using semantic priming paradigms to measure the integrity of the features underlying concepts in semantic dementia (SD) reported differential impairment, in that functional features appeared to be more robust to brain damage than other features, such as perceptual ones. However, these prior studies were single case reports and the inclusion of too many heterogeneous features under the "functional features" heading casts doubts on their apparent preservation. To verify the robustness of functional features compared with perceptual ones, we carried out a group study where we deliberately restricted the exploration of semantic features to two clearly defined types of attribute: visuoperceptual ("visual") versus contextual-functional ("contextual"). We administered an implicit lexical-decision priming task to $8 \mathrm{SD}$ patients and 31 healthy matched controls, at baseline. Four of the patients underwent a follow-up assessment at one year. For controls, we found a significant priming effect in the visual condition, but not in the contextual one, whereas the SD group exhibited the reverse pattern of performances. The follow-up data provided evidence of the robustness of the dissociation between priming performances in the two attribute conditions. The fact that a particular priming effect was observed in the SD patients but not in controls could be regarded as a sign of semantic disequilibrium. Since perceptual features have been shown to be a core determinant of similarity-based/taxonomic relationships, whereas complementary-based/thematic processing relies mainly on contextual relationships, we interpreted our findings in terms of the differential recruitment of one of the two systems of semantic relationships (taxonomic vs. thematic). Moreover, these two distinct and parallel systems have previously been reported to coexist - and compete - in healthy adults. We thus argue that controls automatically drew on similarity-based/taxonomic relationships, leading to a significant priming effect for visual features but not for contextual ones. By contrast, their impaired perceptual features forced the SD patients to resort to the system of thematic relationships.

Keywords: semantic dementia, semantic priming paradigm, visuoperceptual features, contextual-functional features, taxonomic relationships, thematic relationships. 


\section{Introduction}

Semantic dementia (SD) is a rare subtype of frontotemporal lobar degeneration (Moreaud et al., 2008; Neary et al., 1998; Snowden et al., 1989). It arises out of temporal lobe atrophy, often bilateral but predominantly on the left side (Chan et al., 2001; Hodges et al., 1992). SD is characterized by a gradual and a selective loss of conceptual knowledge, resulting in limited vocabulary in speech, poor comprehension, and deficits in the identification of objects and persons in different input modalities (Bozeat et al., 2000; Luzzi et al., 2007; Snowden et al., 2004). While conceptual knowledge distressingly collapses as the disease progresses, language remains fluent and well-structured, without any phonological or grammatical errors, and only subtle abnormalities in the syntactic structure of SD patients' speech have been reported (Meteyard and Patterson, 2009). General intellectual ability, dayto-day memory and visuoperceptual abilities remain relatively spared. Activities of daily living are also relatively preserved until the later stages of the disease.

Semantic breakdown in SD is currently presented as "a selective impairment to semantic abilities that affects all modalities of reception and expression, for all kinds of concepts, more or less equally, and it is the consequence of relatively focal brain lesions" (Patterson et al., 2007; p. 978). Although SD patients often exhibit a significant deterioration in the attributes of underlying concepts, Lambon Ralph et al. (2003) used explicit semantic tasks (naming to description, description-to-picture matching, and verbal definitions) to show that functional/associative features fare better than sensory/perceptual ones.

Patients' performances on explicit semantic tasks could, however, potentially be biased by the activation of intentional and deliberate processes (Ober, 2002), thus increasing the probability of impairment due to extra-semantic processes. For this reason, it is advisable to use an implicit assessment when exploring the organization of conceptual knowledge. Semantic priming paradigms are one of the methods that are currently used to measure the 
integrity of semantic knowledge. Priming tasks reduce intentional processes and promote automatic access to semantic knowledge. Operationalized in a lexical decision task, these implicit paradigms require participants to decide as quickly and as accurately as possible whether a letter string constitutes a real word. This word is preceded by the brief presentation of a prime word that is either related or unrelated semantically to the target word. Based on spreading activation theory, and its assumptions of an interconnected network of concepts (Collins and Loftus, 1975), these paradigms trigger the automatic activation of all the concepts connected to the prime word, such that short reaction times (RTs) can be assumed to reflect closeness between concepts (i.e., between the prime and target words) in the semantic network.

To our knowledge, only five studies have used priming paradigms, operationalized in implicit lexical-decision tasks to measure the integrity of semantic knowledge in SD patients (Laisney et al., 2011; Moss et al., 1995a; Nakamura et al., 2000; Rogers and Friedman, 2008; Tyler and Moss, 1998). In most of these studies, the primed monitoring tasks explored different kinds of semantic relations between concepts, comparing category superordinates/coordinates with unspecified attributes or functional features within the same experimental design.

Disturbed priming effects were reported when the implicit assessment focused on category superordinate (e.g., "walnut" priming "wood") and/or coordinate relationships (e.g., "cherry" priming "apple"). Three studies failed to demonstrate any priming effect at all in these conditions (Moss et al., 1995a; Nakamura et al., 2000; Rogers and Friedman, 2008), while Laisney et al. (2011) observed an abnormally increased priming effect in the two category-coordinate conditions (distant coordinate relationships: "whale" priming "shark"; and close coordinate relationships: "bee" priming "wasp"). Moreover, the magnitude of this hyperpriming effect was greater for close coordinate conditions than for distant ones. This last 
result was underpinned by the extinction of the semantic priming effect in the distinctive attribute condition in the SD group (e.g., "zebra" priming "stripes"). In accordance with Chertkow et al. (1989), Laisney et al. (2011) interpreted this hyperpriming effect as the result of disturbed semantic knowledge. More specifically, they regarded it as reflecting the loss of distinctive attributes. Since the prime and the target could no longer be distinguished, an overpriming condition was generated (Giffard et al., 2001, 2002). In a longitudinal study in Alzheimer's disease (AD), Giffard et al. (2002) found that the hyperpriming effect was purely transient, corresponding to a narrow window of opportunity as the semantic system continued to deteriorate. The extensive semantic knowledge loss subsequently spread to every feature of the concepts, with the result that priming effects could no longer be observed in any of the conditions.

Priming studies assessing attribute integrity in SD patients have yielded rather conflicting results, leading to divergent conclusions regarding the deterioration in semantic features. While two earlier case reports (Moss et al., 1995a; Tyler and Moss, 1998) had highlighted a surprising preservation of the priming effect in the functional attribute condition in two SD patients (PP and AM), two later studies (Laisney et al., 2011; Rogers and Friedman, 2008) failed to find any priming effect in attribute conditions in SD groups. These apparently conflicting results may stem from the fact that these two recent studies were not designed to compare the integrity of different kinds of features. Moreover, Rogers and Friedman (2008) did not provide any details about the types of features they used. Studies making a more fine-grained distinction between different types of attributes have reported differential priming patterns. In the first case study (Moss et al., 1995a), PP exhibited spared semantic priming for functional features (e.g., "shampoo" priming "hair"), but no priming effect for category-coordinate relationships (e.g., "cat" priming "dog"). In the second case study, Tyler and Moss (1998) assessed the integrity of two kinds of features (functional: 
"crocodile" priming "river"; and perceptual: "crocodile" priming "green") and two category relations (superordinate: "crocodile" priming "animal"; and coordinate: "crocodile" priming "alligator"). AM underwent the same testing session three times over an 18-month period. On initial testing, AM showed normal priming effects in the two attribute conditions, but no priming in the category conditions. At the 11-month follow up, functional attributes continued to prime robustly, but priming was no longer observed in the other conditions, including perceptual attributes.

Nonetheless, various methodological shortcomings may partially account for the longer preservation of priming effects in the functional condition. One could argue that the features included under the heading of so-called "functional properties" in the experiments conducted by Moss et al. (1995a) and Tyler and Moss (1998) were heterogeneous. In the former, Moss et al. (1995a) combined two kinds of relationships in the functional condition: a set of priming pairs where the prime consisted in something that was used to perform an action on the target (e.g., "broom" - "floor") and another set of priming pairs sharing contextual relationships (i.e., frequent co-occurrence, with the target referring to a typical component of the event or script evoked by the prime: "theater" - "play"). In Tyler and Moss' priming task (1998), this heterogeneity was even more striking since a careful examination of the kinds of features included in the functional condition highlighted quite different kinds of relationships between the primes and the targets. Under the same « functional » label, the primes and the targets could in fact share "used to perform an action" relationships (e.g., “desk" priming "work"), contextual relationships (e.g., "crocodile" priming "river"), as well as word pairs containing strong lexical associations, i.e. relationships between two concepts in idiomatic expressions, proverbs and quotations (e.g., "fox" priming "sly"). Such heterogeneity makes it hard to draw inferences about the status of so-called "functional" features. Indeed, Rogers and Friedman (2008) have claimed that the lexical associations involve nonsemantic 
processing. In their semantic priming task, they included this kind of relationship as a control condition (e.g., "needle" priming "haystack") and observed a normal priming effect in SD patients. Moreover, "used to perform an action" relationships could, to some extent, implicate the visual object affordances (i.e., mechanisms that support object use directly from visual and/or tactile input) which were isolated by Hodges et al. (2000) as one of the factors accounting for spared abilities to use objects in SD. We could thus ascribe the spared and robust priming effect previously observed in SD patients to the excessively broad types of attributes included under the label "functional condition". This lack of boundary lines between attributes could yet be expected, given the theoretical account underpinning their study. Indeed, Tyler and Moss (1998) compared perceptual versus functional features in relation to sensory/functional theory (SFT; Warrington and Shallice, 1984). This theoretical account assumes that semantic memory is divided into two subsystems, where knowledge about concepts is topographically organized according to the properties that are most distinctive for a given domain (living vs. nonliving concepts). More specifically, SFT predicts that the identification of living entities depends mainly on sensory features, whereas functional features are critical for the representation of nonliving items. This theory is inherently flawed, in that it is hard to find functional attributes that are equally salient for both living and nonliving entities. This problem had led to the extension of functional properties to associative features and encyclopaedic knowledge for living entities (Tyler and Moss, 1997). Tyler and Moss (1998)'s reference to SFT could thus explain the apparent heterogeneity within their set of functional attributes. Moreover, we identified another methodological bias in Tyler and Moss' study (1998) that could account for the robustness of functional features since the set of targets in that priming condition contained both nouns and verbs (e.g., "cherry" priming "eat"). Action verbs processing was yet demonstrated to rely on frontalsubcortical circuits (Davis et al., 2010) and to be virtually preserved in semantic dementia 
(Silveri et al., 2003).

In the present study, we sought to investigate the nature of semantic disorders in SD patients by means of an implicit lexical-decision priming task, focusing our analysis on two different types of attributes: visuoperceptual ("visual") versus contextual-functional ("contextual"). The purpose of the study was thus to verify the robustness of functional features compared with visual ones in a group of SD patients and after limiting the features included under the functional heading to one clearly defined subtype (i.e., contextual relations between two entities). Contextual attributes had the added advantage of being easier to find for both living and nonliving concepts. A second goal was to determine whether this hypothetically differential deterioration in perceptual versus functional features persists as the disease progresses, by conducting a second assessment of patients at one-year follow up.

\section{Methods}

\subsection{Participants and background data}

\subsubsection{Semantic dementia}

Eight patients who met the diagnostic criteria for SD (Neary et al., 1998) were included in this study after providing their written informed consent. All of them were native French speakers and were followed at the memory clinic of Rennes University Hospital (see Table 1 for individual demographic and clinical features).

To establish their cognitive profile, we administered a comprehensive neuropsychological battery to the SD patients in a separate session just before they carried out the experimental task (see Table 2 for individual scores). This neuropsychological battery consisted of an assessment of their general cognitive functioning (Raven's Coloured Progressive Matrices, RCPM; Raven et al., 1998; Dementia Rating Scale, DRS; Mattis, 1976), working memory (digit span forward and backward, Wechsler Adult Intelligence 
Scale-Revised, WAIS-R; Wechsler, 1981), nonverbal episodic memory ("La Ruche" visuospatial learning task; Violon, 1984; delayed recall of the Rey-Osterrieth Complex Figure Test, ROCF - Form A; Osterrieth, 1944), and explicit semantic memory (picture-naming task, verbal and visual semantic matching tasks from the GRECO neuropsychological semantic battery, BECS-GRECO; Merck et al., 2011). The semantic battery assesses the integrity of the same 40 items (20 biological entities and 20 artifacts) in both verbal and visual input modalities (words and black-and-white drawings). Language skills (regular and irregular word reading; single-word repetition of the Boston Diagnostic Aphasia Examination, BDAE; Goodglass and Kaplan, 1972) and visuoperceptual performances were also assessed (copy condition of the ROCF - Form A; embedded figures subtest of the "Protocole d'Evaluation des Gnosies Visuelles”, PEGV; Agniel et al., 1992; Benton Facial Recognition Test, BFRT; Benton et al., 1994).

All the patients exhibited normal performances on RCPM, which contrasted with their impaired overall DRS scores, as expected, given the well known vocabulary and comprehension deficit in SD. Furthermore, all the patients displayed an apparently spared day-to-day memory. Only one of them (SD2) scored below the normal range on one of the two episodic memory tasks. Regarding their performances on the explicit semantic assessment, they were all significantly impaired on picture naming. Six of them performed abnormally on both the verbal and visual semantic matching tasks, with only SD5 and SD7 exhibiting a deficit restricted to the verbal version of the task. Their overall level of semantic impairment on these explicit tasks was expressed under three labels: mild, moderate and severe (Table 2). Finally, none of them displayed a deficit on language tasks that did not critically depend on semantic object knowledge (i.e., word repetition and regular word reading). One patient (SD7)'s performance was impaired on a visuoperceptual task (BFRT).

The neurological examination was normal for all eight SD patients. Neuroimaging 
(MRI scans) revealed atrophy predominantly in the temporal lobes. Atrophy was bilateral, but more pronounced on the left side in four patients (Table 1). Three patients exhibited an almost left-sided temporal atrophy (SD4, SD7, and SD8) and one left-handed patient presented with

right temporal atrophy (SD6). Seven patients also underwent ${ }^{18}$ fluorodeoxyglucose PET (FDG-PET) imaging, which revealed good topographical concordance between hypometabolism and areas of atrophy.

Only four of the patients (SD2, SD4, SD5 and SD6) underwent a follow-up assessment at one year. Indeed, one patient presented with such a dramatic decline in semantic abilities that she was no longer able to perform the task, another one deceased (by committing suicide) and the two remaining participants were not available to participate at follow up. The four patients were administered the same neuropsychological battery as before, including the experimental implicit lexical-decision task. The neuropsychological data at follow up essentially revealed a further small decline in overall DRS scores for three patients (SD2, SD4 and SD6). All four patients exhibited poorer performances on at least one of the three explicit semantic tasks. Their overall semantic impairment on these explicit tasks (i.e., mild, moderate and severe) yet remained at the same level as at the baseline (Table 2).

\subsubsection{Controls}

Thirty-one healthy volunteers were recruited (see Table 1 for demographic data). All were native French speakers and had no history of neurological or psychiatric disorders, or drug or alcohol abuse. Prior to taking part, they all provided their written informed consent. They were matched with the SD patients for age $(U=90, z=-1.186, p=0.249)$, sex $\left(C h i^{2}(1)\right.$ $=0.315, p=0.575)$ and years of education $(U=116.5, \mathrm{z}=-0.265, p=0.798)$. All these control participants were included after undergoing a short screening assessment to rule out any overall cognitive impairment (all DRS scores were above the cut-off point) or lexical semantic disorder (all scores above the cut-offs on the BECS GRECO subtests: picture- 
naming task, mean $=39.1 \pm 1$, range $=37-40$; verbal semantic matching task, mean $=39.9 \pm$ 0.5 , range $=38-40 ;$ visual semantic matching task, mean $=39.9 \pm 0.3$, range $=39-40 ; 6$-item verbal semantic questionnaire, mean $=237.4 \pm 1.3$, range $=235-240)($ Table 2$)$.

\subsection{Experimental materials and design}

\subsubsection{Priming stimuli}

In the implicit semantic priming task, the primes were the names of biological entities or artefacts, whereas the targets were feature associated with the prime concepts. Targets could be either a proper noun or an adjective corresponding to a visual or contextual feature. In the visual condition, word pairs were selected so that the target referred to a visuoperceptual features (colour, shape, distinctive part) of the prime-object (e.g., "ostrich" priming "neck"). In the contextual condition, the target referred to an object currently associated with the prime in the environment (e.g., "bed" priming "pillow"). If all the visual word pairs and some contextual ones involve part-whole relationships, a substantial difference exists between these two sets of items. In the visual condition, word pairs share an inextricable part-whole link since one item is a component of the other, in an inseparable way (e.g., "ostrich-neck"; “cat-whiskers"; "broom-handle”). In contextual condition, items were separable, so that one item can exist independently from the other (e.g., "ring-diamond", “squirrel-hazelnut”; "envelope-stamp").

The targets were composed of one, two or three syllables (see Table in supplementary Material). The word pairs were associatively and semantically related and were selected from the data collected by Laisney et al. (see Laisney et al., 2011, for more methodological details). Briefly, these word pairs were generated by students $(N=129)$ in two verbal association tasks. In these two tasks, the students had to produce the first word that came to mind in response to inductor words. We retained 44 semantically related prime-target pairs: 22 priming pairs with a visual attribute and 22 others with a contextual one. In each condition, 
half the items corresponded to living concepts and the other half to nonliving entities. Four subsets of priming pairs were thus constituted: 1) visual attributes for biological entities (e.g., "elephant" priming "tusk"); 2) visual ones for artifacts (e.g., "cap" priming "eyeshade"); 3) contextual attributes for biological entities (e.g., "squirrel" priming "hazelnut"); and 4) contextual ones for artifacts (e.g., "small boat" priming "oar"). We added 44 unrelated pairs (e.g., "jail" priming "stamp") to the 44 semantically related pairs (e.g., "envelope" priming "stamp"). We then added a further 60 filler pairs (e.g., "stone" priming "violin") to reduce the proportion of semantically related word pairs to below 30\%. Our lexical-decision task also included 148 pairs where the prime was a word and the target a pseudoword (e.g., "night" priming "guilcha"). The pseudowords were constructed in accordance with the following rules: they were all pronounceable, and they all respected the orthographic structure of the French language. Like the target words, these pseudowords were composed of one, two or three syllables. The final version of our lexical-decision priming task therefore contained 296 pairs.

Each target (word or pseudoword) was presented twice in this monitoring task, while all the primes were encountered once, so that a target could never be linked to the same prime twice. The targets differed between the visual and the contextual conditions. In each attribute condition, the targets appeared once with a semantically related prime and again with an unrelated prime.

The targets of the four priming pairs subsets (visual attributes for biological entities, visual ones for artifacts, contextual attributes for biological entities, contextual ones for artifacts) were matched for lexical frequency (Lexique database; New et al., 2004), one-way analysis of variance (ANOVA), $F(3,43)=1.233, p=0.310$, for letter length, $F(3,43)=$ 0.733, $p=0.539$, and for syllable number, $\operatorname{Chi}^{2}(6)=4.32, p=0.633$. In both semantically related and unrelated conditions, the primes of these four subsets were also matched for 
lexical frequency (primes for the related condition, $F(3,43)=2.066, p=0.120$; primes for the unrelated condition, $F(3,43)=0.955, p=0.423$ ), for letter length (primes for the related condition, $F(3,43)=2.101, p=0.115$; primes for the unrelated condition, $F(3,43)=1.571, p$ $=0.211$ ), and for syllable number (primes for the related condition, $\operatorname{Chi}^{2}(6)=10.22, p=$ 0.116; primes for the unrelated condition, $\left.\operatorname{Chi}^{2}(6)=9.14, p=0.166\right)$. We also compared these four subsets in terms of the strength of the verbal association between prime and target in the semantically related word pairs. The frequency with which a word was produced in response to an inductor in the verbal association task was taken as a measure of the strength of that verbal association (Laisney et al., 2011). Our four priming pairs subsets did not differ on this variable, $F(3,43)=0.705, p=0.555$. Matching word pairs for this confounding variable is by far required since Moss et al. (1995b) and Lucas (2000) emphasized that verbal association can lead to a "boost" in priming effect, above the effect of semantic relationships alone.

The 296 pairs were split into three blocks that were counterbalanced between participants. Within each block, no target appeared twice, and items were pseudo-randomized so that the block never began with a related pair and there was no sequence of three identical consecutive responses (positive or negative).

\subsubsection{Priming procedure}

The design of our lexical-decision priming task was derived from Giffard et al. (2001, 2002, 2003) and Laisney et al. (2011). Stimuli were presented using SuperLab Pro 4.5 software (Cedrus Corporation, San Pedro, CA, USA). Responses were produced and recorded using the RB-830 8-button response pad (Cedrus Corporation, San Pedro, CA, USA). Participants were instructed to answer with their dominant hand by pressing one of the two coloured buttons (green button for "yes" and red button for "no").

Before the test, the participants underwent a practice session featuring 34 word pairs: four related pairs, 15 unrelated pairs and 15 word-pseudoword pairs. Participants were asked 
to read each prime and target out loud, in order to train their ability to read primes displayed only briefly. This training session lasted until each participant was able to read each word and pseudoword easily and accurately.

Each lexical-decision trial began with a fixation cross that remained in the middle of the screen for $1000-1500$ msec (duration randomized across trials). Next, a prime word was displayed for $200 \mathrm{msec}$, followed by a blank screen for $50 \mathrm{msec}$. The target then appeared and remained on the screen until a response was recorded. The stimulus onset asynchrony (SOA) was set at $250 \mathrm{msec}$. A short SOA is recommended to reduce the use of expectancy strategies (i.e., the use of a prime as a cue for generating possible target items related to the prime; Neely, 1977; Ober, 2002) and promote the involvement of automatic processes. There was a 1000 msec inter-stimulus interval between each trial.

Each block was separated by a short break lasting 5 minutes. At the beginning of each block, participants were instructed as follows: "You will be shown word pairs that you must read to yourself. For each word pair, you must determine whether or not the second word belongs to the French language. Press the green button for "yes, the letter string is a French word", and the red button for "no, the letter string is not a French word". You must respond as quickly as possible." We focused the instructions on RT speed to optimize the intervention of automatic processes, even though a recent study (Stefaniak et al., 2010) revealed a smaller impact of manipulating instructions (speed vs. accuracy) on the responses of older adults compared with younger ones, in an implicit lexical-decision task.

\subsection{Statistical analysis}

Statistical analyses were performed using SPSS Statistics 12.0 software (SPSS Inc., Chicago, IL, USA). Analyses were carried out first on accuracy (percentage of correct responses), then on $R T s$. In the RT analyses, we only considered correct responses and ruled out extreme outliers. Outliers were defined at an individual level and corresponded to any 
score more than three interquartile ranges (IQRs) from the rest of the scores (indicated by asterisks in the SPSS boxplot graphs).

We focused our analyses on priming effect measures. We therefore ran group (controls vs. SD patients) x link (related vs. unrelated) x attribute (visual vs. contextual) mixed-design ANOVAs on the raw data, with link and attribute as repeated measures and group as a between-participants factor. As planned comparisons, we used paired-samples $t$-tests to compare performances on related versus unrelated pairs for the two priming conditions taken together, then, separately for the visual and contextual attributes. We then compared the two groups' performances on every condition (related for visual, unrelated for visual, related for contextual, unrelated for contextual). Since each of the four priming pairs subsets was only composed of 11 items (i.e., visual attributes for biological entities, visual ones for artifacts, contextual attributes for biological entities and contextual ones for artifacts), the contrast between the priming effects obtained for those subsets should be considered with more caution. As subsidiary analyses, we thus performed group (controls vs. SD patients) x link (related vs. unrelated) $\mathrm{x}$ attribute (visual vs. contextual) $\mathrm{x}$ domain (living versus non living entities) ANOVA, as well as planned within-groups analyses to determine whether or not there is any effect of the domain of knowledge upon the priming results and to identify in which priming pairs subset a significant effect was mainly observed.

Thereafter, we ran a link (related vs. unrelated) x attribute (visual vs. contextual) ANOVA on the raw RT data transformed into priming percentages (priming percentage $=$ [mean RT for unrelated condition - mean RT for related condition] / mean RT for unrelated condition *100). We used the priming percentages - first proposed by Balota et al. (1999), then recommended by Giffard et al. $(2001,2002)$ - to reduce any impact of cognitive slowing on the magnitude of the patients' priming effect. 
Finally, we carried out intra-individual analyses on the follow-up data for the four SD participants (SD2, SD4, SD5 and SD6). These analyses helped us to determine the number of patients who displayed a dissociation between the two attribute conditions, at the two assessment times. For this purpose, we employed the Bayesian criterion for dissociations in case studies, associated with the Bayesian standardized difference test (BSDT) developed by Crawford et al. (2010). This programme allowed us to identify a "strong dissociation" (i.e., meeting the following criteria: the standardized difference between the individual's scores in the $\mathrm{X}$ and $\mathrm{Y}$ conditions of a task must be significant, as must a deficit in at least one of the two conditions). This statistical method was applied to performances (RTs only) at baseline and at one-year follow up for each of the four SD patients.

For the overall analyses, all tests were two-tailed and the statistical level of significance was set at $p=0.05$.

\section{Results}

\subsection{Semantic priming effect at baseline}

\subsubsection{Accuracy}

A group $\mathrm{x}$ link $\mathrm{x}$ attribute ANOVA on the percentage of correct responses only showed a main effect of group, $F(1,37)=18.432, p<0.001$, in that the SD patients were less accurate than controls (Table 3 ). No main effect was observed for either link, $F(1,37)=$ $0.068, p=0.795$, or attribute, $F(1,37)=1.724, p=0.197$. Neither the group $\mathrm{x}$ link, $F(1,37)=$ $0.068, p=0.795$, nor the link $\mathrm{x}$ attribute, $F(1,37)=0.745, p=0.394$, interaction reached significance. The group $\mathrm{x}$ attribute interaction tended towards significance, $F(1,37)=3.776$, $p=0.06$. Planned comparisons revealed no significant differences explaining this trend towards significance (Table 3). Otherwise, the group $\mathrm{x}$ link $\mathrm{x}$ attribute interaction was not significant, $F(1,37)=1.252, p=0.270$. 
Finally, neither controls nor SD participants' accuracy differed across priming conditions (visual related vs. contextual related, for controls: $t(30)=1.680, p=0.103$; for SD patients: $t(7)=-0.768, p=0.468)$. Besides, we failed to show any difference in accuracy between the two domains of knowledge (living versus non living entities) in both controls and SD patients (Controls, related condition: $t(30)=1.680, p=0.103$, unrelated condition: $t(30)=$ 0.571, $p=0.572 ; S D$ patients, related condition: $t(7)=-0.001, p=1$, unrelated condition: $t(7)$ $=-1.656, p=0.142)$.

\subsubsection{Reaction times (RTs)}

A group $\mathrm{x}$ link $\mathrm{x}$ attribute ANOVA indicated significant main effects of group, $F(1$, $37)=58.198, p<0.001, \eta^{2}$ partial $=0.611$, link, $F(1,37)=7.139, p=0.011, \eta^{2}$ partial $=0.162$, and attribute, $F(1,37)=12.823, p=0.001, \eta^{2}$ partial $=0.257$. The link $\mathrm{x}$ attribute interaction reached significance, $F(1,37)=17.631, p<0.001, \eta^{2}$ partial $=0.323$, unlike the group $\mathrm{x}$ link, $F(1,37)=0.041, p=0.840$, and group $\mathrm{x}$ attribute, $F(1,37)=0.242, p=0.626$, interactions. The group $\mathrm{x}$ link $\mathrm{x}$ attribute interaction was significant, $F(1,37)=32.190, p<0.001, \eta^{2}$ partial $=0.465$

Planned within groups comparisons indicated a significant overall priming effect for controls (i.e., when both kinds of features were collapsed), with shorter mean RTs in the related condition than in the unrelated one (related condition: mean $=625.4 \pm 89.2$; unrelated condition: mean $=644.8 \pm 88.4 ; t(30)=-3.664, p<0.001)$, but no such overall priming effect for the SD patients (related condition: mean $=1050.6 \pm 282.1$; unrelated condition: mean $=$ $1076.4 \pm 264.7 ; t(7)=-1.121, p=0.299)$. Furthermore, when each attribute condition was considered separately, we found contrasting results for the SD group compared with controls (Table 3). For controls, a significant priming effect was revealed for visual attributes (unrelated vs. related pairs, $t(30)=-4.705, p<0.001$ ) and no priming effect for contextual ones (unrelated vs. related pairs, $t(30)=-1.143, p=0.262$ ). These contrasted performances 
could not be explained by any differential level of complexity between the two attribute priming conditions (for controls: visual related vs. contextual related conditions, $t(30)=$ $1.881, p=0.07)$. As contrasted with the controls' pattern of performances, the SD participants exhibited an absence of priming in the visual condition (unrelated vs. related, $t(7)=1.105, p=$ 0.306 ), but a significant priming effect in the contextual one (unrelated vs. related, $t(7)=-$ 6.771, $p<0.001$ ). For each planned comparison (related for visual, unrelated for visual, related for contextual, unrelated for contextual), controls responded significantly faster than the SD participants, even after the Bonferroni correction for multiple comparisons (all $p \mathrm{~s} \leq$ $0.001)$.

As subsidiary analysis, we performed a group $\mathrm{x}$ link $\mathrm{x}$ attribute $\mathrm{x}$ domain ANOVA which confirmed and replicated the previous results and showed significant main effects of group, link, attribute and domain (all $p s<0.01)$. Besides, this analysis indicated no significant group $\mathrm{x}$ attribute $\mathrm{x}$ domain interaction, $F(1,37)=1.140, p=0.293$, while group $\mathrm{x}$ link $\mathrm{x}$ domain interaction tended towards significance $F(1,37)=3.776, p=0.06$, and link x attribute $\mathrm{x}$ domain interaction reached significance, $F(1,37)=15.891, p<0.001, \eta^{2}$ partial $=0.300$. Finally, the group $\mathrm{x}$ link $\mathrm{x}$ attribute $\mathrm{x}$ domain interaction was significant, $F(1,37)=12.968, p$ $=0.001, \eta^{2}$ partial $=0.260$. In the control group, planned comparisons yielded a significant priming effect in the visual condition for both biological and artifacts concepts (biological, unrelated versus related, $t(30)=-2.380, p=0.024$; artifacts, unrelated versus related, $t(30)=-$ 4.495, $p<0.001$ ), but no priming effect in the contextual one, regardless the domain of knowledge (biological, unrelated versus related, $t(30)=-0.651, p=0.520$; artifacts, unrelated versus related, $t(30)=-1.257, p=0.219)$. In the SD group, the same analyses revealed a significant priming effect in the contextual condition for only living entities (biological, unrelated versus related, $t(7)=-2.619, p=0.034$; artifacts, unrelated versus related, $t(7)=-$ 1.436, $p=0.194)$. In the visual condition, an unexpected trend towards significance was 
observed for living entities, in that RTs for related pairs tended to be longer than for unrelated ones (biological, related pairs mean $=1137.7 \pm 345.5$, unrelated pairs, mean $=993.5 \pm 231.9$, $t(7)=2.187, p=0.065 ;$ artifacts, unrelated versus related, $t(7)=-1.293, p=0.237)$.

\subsubsection{Priming percentages for RTs}

A group $\mathrm{x}$ attribute ANOVA failed to reveal a significant main effect of group, $F(1$, $37)=0.157, p=0.694$, but the attribute effect, $F(1,37)=11.074, p=0.002, \eta^{2}$ partial $=0.230$, was significant. The group $\mathrm{x}$ attribute interaction was significant, $F(1,37)=25.376, p<$ $0.001, \eta^{2}$ partial $=0.407$. Planned comparisons revealed contrasting patterns of performances between the SD patients and controls, with higher priming percentages for the SD patients than for controls in the contextual condition $(U=24, z=-3.478, p<0.001)$, and lower percentages in the visual one $(U=67, z=-1.982, p=0.048)$ (Fig. 1).

\subsection{Semantic priming effect at follow up}

One year later, we administered the same experimental priming task to SD2, SD4, SD5 and SD6 again. Only two of these four SD patients had initially exhibited a significantly strong dissociation between the priming effects for the two attributes (SD2: BSDT, Z-DCC = -7.699, $p<0.0001$, and SD5: BSDT, Z-DCC $=-6.861, p<0.0001$; compared with SD4: BSDT, Z-DCC $=0.606, p=0.556$, and SD6: BSDT, Z-DCC $=-1.871, p=0.072$ ). However, all four patients displayed a strong dissociation one-year later (SD2: BSDT, Z-DCC $=-5.433$, $p<0.0001$; SD4: BSDT, Z-DCC $=-3.966, p<0.001$; SD5: BSDT, Z-DCC $=-2.266, p=$ 0.038; SD6: BSDT, Z-DCC $=-2.336, p=0.028)$.

SD2, SD4 and SD5 exhibited an absence of priming in the visual condition, but a significant priming effect in the contextual condition. Only SD6 exhibited a significantly increased priming effect for the contextual attributes, contrasting with a slightly lower (but still within the normal range) effect for the visual ones. 
It is worth noting that there is no clear link between the overall level of semantic impairment (i.e., performances on the three explicit semantic tasks) and the presence or the absence of a strong dissociation between the priming effects in the two attribute conditions.

Taken together, we can briefly sum up these results as follows: the SD patients generally displayed the opposite pattern of performances to controls when analyses focused on the two attribute conditions. The SD group showed no priming for visual attributes, but a significant priming effect for contextual ones. Furthermore, the follow-up data provided evidence of the robustness of the dissociation between priming performances in the two attribute conditions. This dissociation persisted between baseline and follow up, and the number of patients exhibiting this strong dissociation increased from two SD patients at baseline to four at one-year follow up.

\section{Discussion}

This study was designed to explore the integrity of two types of features: visuoperceptual versus contextual/functional. More specifically, we sought to verify the robustness of previous findings (i.e., the preservation of functional features vs. the impairment of perceptual ones) by restricting the features included under the functional heading to contextual ones only. A second goal was to determine whether this hypothetical differential deterioration in perceptual versus functional attributes remained significant as the disease progressed, which is why we assessed four of the patients at one-year follow up.

At a group level, we failed to find an overall priming effect (i.e., both kinds of features collapsed) for the SD patients, unlike controls. The absence of an overall priming effect in the SD patients was in line with previous findings (Nakamura et al., 2000; Rogers and Friedman, 2008). However, when we considered the two types of semantic features separately, we observed contrasting patterns of performances for the SD patients and controls. The latter displayed significant priming in the visual condition and no priming effect in the contextual 
one, whereas the SD participants exhibited an absence of priming for visual features, but significant priming for contextual ones. We also found evidence for the robustness of this effect in the SD patients. Intra-individual analyses indicated that the dissociation (i.e., no priming effect for visual attributes and a significant priming effect for contextual ones) remained significant between baseline and follow up. Moreover, the number of patients exhibiting a strong dissociation also increased between these two assessment times, since all four SD patients met the Bayesian criterion for strong dissociation at one-year follow up. These results are in accordance with Tyler and Moss' core findings (Moss et al., 1995a; Tyler and Moss, 1998). Through the use of semantic priming paradigms, these authors were able to determine that functional attributes are preserved for longer than category relations (Moss et al., 1995a; Tyler and Moss, 1998) and perceptual attributes (Moss et al., 1995a). Their longitudinal study (Tyler and Moss, 1998) also emphasized that functional properties are more resistant to brain damage. Although we sought to bypass the potential methodological shortcoming identified in these studies (i.e., the inclusion of extremely heterogeneous features under the functional heading), by restricting functional features to a contextual subtype, we obtained identical findings. We also observed a deterioration in visuoperceptual features (i.e., absence of the priming effect in this condition) at an early stage in the disease. This agreement between previous findings and our results suggest that impairment of visuoperceptual features, as opposed to contextual-functional attributes, is a key deficit in SD. The status of the latter is still uncertain and raises further issues.

We claim first of all that the priming effect for contextual attributes is the result of semantic change in SD patients, rather than an artifact arising simply from cognitive slowing, as was previously proposed by Nebes et al. (1989). According to these authors, the probability of exhibiting shorter RTs than controls for semantically related pairs is higher when patients display longer RTs for unrelated pairs. This argument was advanced mainly to disprove the 
hyperpriming effect reported in AD using lexical-decision priming tasks (Chertkow et al., 1989). Hyperpriming was thus regarded as an artifact resulting from general cognitive slowing. In our study, as expected, we also found a slowing of lexical-semantic processing in our SD group, as their RTs for unrelated pairs were longer than those of controls. Nevertheless, our main finding remained significant even when analyses were carried out on priming percentages, which tend to correct the priming effect by taking account of RTs for unrelated pairs.

Second, we consider that our results mainly reflect genuine semantic mechanisms rather than the intervention of nonsemantic lexical processes. The involvement of lexical processes is known to enhance the priming effect, as Rogers and Friedman (2008) reported significant and normal priming effects in their SD group in a lexical associative condition. More recently, Perri et al. (2011) argued that studies using verbal association tasks to select their semantically related word pairs cannot rule out an intervention of lexical processes in their priming effects. Although our items were also chosen from two verbal association tasks, we believe that any minimal lexical intervention processes could not account for the priming pattern observed in the SD patients, as we had taken the methodological precaution of matching the four priming pair subsets on the strength of verbal association. Our main finding can thus be interpreted in terms of semantic mechanisms resulting in differential patterns of performances in controls and the SD group.

Third, we argue that the priming effect observed in the SD patients in the contextual condition can be regarded as a sign of a semantic knowledge disequilibrium, rather than overspared contextual features. As proposed by Perri et al. (2011), a priming effect that is observed in patients without any significant corresponding effect in controls presumably reflects semantic deterioration (cf. previous interpretations of hyperpriming effects). Arguments in favour of a semantic deficit underlying the abnormally increased priming effect 
in patients were first put forward by Chertkow et al.'s study (1989) in AD. Giffard and colleagues $(2001,2002)$ also reported hyperpriming in the category-coordinate condition in AD patients, interpreting it as a reflection of semantic deterioration. They hypothesized that an abnormally increased priming effect stems from a decline in the specific semantic features that are needed to discriminate between close exemplars of the same semantic category (e.g., "tiger" - "lion"). As the "tiger lost its stripes" and the "lion, its mane", the remaining, spared features were shared by both entities and entirely overlapped, leading to confusion between the two concepts. These assumptions were put forward to explain an abnormal "positive" priming effect as a sign of semantic deficit. However, they do not hold here. The hypothesis of abnormally increased priming effects stemming from a deterioration in specific attributes was essentially developed for concepts sharing coordinate relationships. It is far more difficult to apply to contextual attributes where two concepts (e.g., "squirrel" - "hazelnut") share only a contextual relationship and no other obvious common features.

Alternatively, we speculate that the priming effect observed in the contextual condition in our SD patients was indicative of a profound semantic disequilibrium altering the relationship between two distinct and parallel semantic systems. To explain this assumption, we should first specify that contextual attributes are also known as "thematic" relations, referring to complementary roles between two entities. Complementary-based relations can be defined as the frequent co-occurrence of two entities in events or situations, and refers to the link between concepts that occur together in time and space (Denney, 1975). Thematic, or complementary-based, relations are currently contrasted with similarity-based relations, also called "taxonomic" relations. These two systems refer to different relationships between concepts (Lin and Murphy, 2001): the thematic system addresses the external relations between two entities, whilst the taxonomic system refers to the concepts' internal structure and, more specifically, to the categories' features. Preferential recruitment of one or other of 
the systems has previously been demonstrated in childhood, from a developmental perspective. Nguen and Murphy (2003) thus reported a preference for thematic rather than taxonomic categorization in children. Students have also been found to prefer thematic relationships, when required to choose between these two types of categorization (Lin and Murphy, 2001). These two systems have also been reported to coexist in healthy adults. Nevertheless, many studies have yielded more conflicting results. Kalénine et al. (2009) demonstrated an advantage of taxonomic over thematic relationships regarding both RTs and accuracy on a matching task, while Sachs et al. (2008a) failed to highlight any difference between thematic and taxonomic conditions on these two measures in a forced-choice category construction task. Contrasted results were also highlighted in studies using implicit lexical-decision priming tasks. Exploring the specific role of each cerebral hemisphere in semantic processing, visual-half-field behavioural priming studies reported greater priming effect for thematic than taxonomic relationships and also that taxonomic priming effect occurred for longer SOAs (Abernethy and Coney, 1993; Bouaffre and Faita-Ainseba, 2007). These results are in line with fMRI studies investigating the neural correlates of semantic priming for taxonomic and thematic relationships. Indeed, Kotz et al. (2002) demonstrated that healthy adults took longer to respond to taxonomic relations than to thematic ones. More recently, Sachs et al. (2008b) found a larger priming effect in the thematic condition than in the taxonomic one, together with more errors for taxonomic relationships. Sass et al.'s priming study (2009) reported clearer results in favour of thematic processes in healthy adults, as they only found a significant priming effect in the thematic condition, and none for taxonomic relationships. By contrast, Jones and Golonka (2012) failed to replicate these previous findings of differential priming effects for thematic and taxonomic relationships. There are three possible explanations for these overall conflicting results in healthy adults. First, they could stem from inter-individual variability (Mirman and Grazanio, 2012a; 
Simmons and Estes, 2008), in that each participant may differ in the weighting allocated to taxonomic and thematic semantic processing. Second, they may arise from the knowledge domain to which the experimental items belong. Both Sachs et al. (2008 a,b) and Sass et al. (2009) used paradigms in which the words depicted solely nonliving objects, whereas Kalénine et al. (2009) compared biological concepts with artifacts. Moreover, Kalénine et al. (2009) demonstrated a significant interaction between knowledge domain and type of semantic relationship, in that taxonomic relationships were identified more quickly for living entities, and thematic relationships were recognized faster for nonliving ones. Third, Jones and Golonka (2012) interpreted the advantage of thematic over taxonomic relationships in previous priming studies as the consequence of integrative relationships within the thematic word pairs set. The fact that thematic word pairs shared mixed (both thematic and integrative) relationships could potentially explain the greater priming effect observed in that condition compared with the taxonomic one. In their work, Jones and Golonka (2012) isolated integrative relationships as a third kind of semantic relations, distinct from thematic and taxonomic ones. They referred to Estes and Jones (2009)'s study to define the integrative relationships as a link between two concepts which can be easily brought together to create a unitary representation. Integrative relationships include the internal component (e.g., "cherry"-"pit"; "fruit”-“cake") and external component (e.g., "tricycle”-"pedals"; "sirenambulance"). Nevertheless, the authors admitted that integrative and thematic relations are not exclusive and may overlap. In the present study, that kind of semantic relationship is present in our contextual word pairs set (e.g., "oak tree"- "acorn") as well as in our visual one (e.g. "bicycle"-"handlebar"). These additional integrative relationships could exert a possible influence on the priming effects in both conditions. Such an influence cannot therefore be retained as a probable confounding factor explaining our core finding (i.e., the significant priming in the visual condition but not in the contextual one for controls and the 
reverse pattern of performances in the SD patients).

We rather believe that our findings can be interpreted in terms of the differential recruitment of one of these two competing systems. This interpretation holds good even though our priming paradigm did not directly contrast taxonomic versus thematic relations, but rather visuoperceptual versus contextual-functional features. Perceptual features have been shown to be a core determinant of similarity-based/taxonomic relationships (Medin and Ortony, 1989), whereas complementary-based/thematic processing relies mainly on contextual ones. Davidoff and Roberson (2004) were the first to suggest an overlap between perceptual and taxonomic categorization abilities. In a case study, these authors described an aphasic patient (symptoms close to Wernicke's aphasia: LEW) with impairment of both taxonomic and perceptual categorization, contrasting with preserved thematic categorization. Evidence for crucial links between perceptual features and taxonomic relationships has also been forthcoming in fMRI studies. Taxonomic relationships appear to activate neural bases that are commonly reported when perceptual processing is engaged (i.e., visual associated areas, bilaterally), whereas thematic relationships recruit a bilateral temporoparietal network (Kalénine et al., 2009). It is worth noting that the involvement of the temporoparietal junction - known to be involved in motion, action and spatial processing - has been consistently revealed across several studies (de Zubicaray et al., 2013; Mirman and Grazanio, 2012b; Schwartz et al., 2011). Concerning the neural correlates of semantic priming for taxonomic and thematic relationships in lexical-decision tasks, several fMRI studies (Kotz et al., 2002; Sachs et al., 2008b; Sass et al., 2009) revealed that taxonomic relationships require the recruitment of additional areas in the right hemisphere, interpreted as reflecting a more effortful semantic processing than for thematic one. Contrasted to thematic relationships, taxonomic processing resulted in enhanced activations in cuneus (Kotz et al., 2002) - in accordance with Kalénine et al. (2009) - precuneus (Kotz et al., 2002; Sachs et al., 2008b) and 
isthmus of cingulate gyrus (Kotz et al., 2002) and was interpreted as relying on perceptual processing, episodic memory retrieval and on detection of semantic relations. In Sass et al. (2009), a direct comparison between the two semantic relationships revealed an activation in the left superior temporal sulcus for thematic over taxonomic conditions, due to an opposite level of responses in this area. While thematic processing induced response-enhancement in the left STS, response-suppression was observed in taxonomic condition. Partially distinct neural basis and differential level of responses in the same area between the two semantic relationships were also highlighted by Sachs et al. (2011). These authors observed responsesuppression in the right middle frontal gyrus for the taxonomic processing, whereas thematic relationships resulted in response-enhancement in the left inferior frontal gyrus. Sachs et al. (2011) recalled that the right middle frontal gyrus is associated with mental search within the semantic network, higher retrieval effort and decision uncertainty, so that the responsesuppression could be the sign of priming effect as taxonomic processing depends upon perceptual/similarity-based relationships. The left inferior frontal gyrus is involved in executive control of retrieval and selection from the semantic memory, so that the responseenhancement for thematic processing could reflect the spread of activation between connected nodes. Finally, a direct contrast between the two semantic relationships revealed an increased activation for taxonomic relationships in the right insula lobe - known to be involved in working memory and attentional components - while the same area tended to decrease in the thematic condition.

These last results regarding the opposite patterns of responses enhancement and suppression in identical areas between thematic and taxonomic processing could raise the issue of partial reverse neural processing underlying thematic and taxonomic relationships. Furthermore, some authors suggested that those two distinct and parallel systems coexist but also compete in healthy adults (Maguire et al., 2010). In their work using event-related 
spectral perturbation analyses, they demonstrated that theta power increased over right frontal areas for thematic relationships and that alpha power increased over parietal areas for taxonomic ones. They proposed that this increased alpha power may be the consequence of the inhibition of thematic relationships, to give way to taxonomic processing.

Regarding the results of our semantic priming paradigm, we can infer that in controls, similarity-based/taxonomic relationships were automatically advantaged over complementary-based/thematic relationships, leading to a significant priming effect for visuoperceptual features and no priming for contextual-functional ones. In the SD patients, the deterioration of visuoperceptual attributes impeded the similarity-based/taxonomic processes and thus brought complementary-based/thematic relationships to the fore. Such an interpretation is not at variance with previous studies assessing thematic relationships by means of explicit semantic matching tasks (e.g., the Pyramid \& Palm Trees Test; Howard and Patterson, 1992) and demonstrating that SD performed below normal range (Bozeat et al., 2000; Jefferies et al., 2006). Note that in the present study, SD participants exhibited a lower level of performances than controls on both accuracy and RTs in the contextual condition, suggesting that their thematic relationships knowledge is not spared. Nonetheless, that impairment is not discordant with our hypothesis that SD patients rely more upon complementary-based/thematic relationships system (even impaired) than on the similaritybased/taxonomic one.

Additionally, our line of interpretation was strengthened by subsidiary results in the SD group when complementary analyses were focused on the two subsets of living priming pairs. A significant priming effect was reported in the contextual condition for the biological entities while an unexpected trend towards significance was observed in the visual condition for biological entities, in that their RTs for related pairs tended to be longer than for unrelated pairs. That tendency to slowly treat prime pairs might be considered as an extinction of the 
link between a concept and its visual attribute. We speculated this line of interpretation from the Laisney et al. (2011)'s schematic evolution (and involution) of semantic priming effects in relation to semantic memory deterioration. These authors proposed that the priming effects in the distinctive (e.g., "zebra" priming "stripes") and in the shared (e.g., "duck" priming "feather") feature conditions progressively and dramatically fall under the normal mean at severe levels of semantic deterioration, until a possible negative priming effect might occur. This negative priming effect could thus be considered as a sign of a distressing semantic breakdown, so that a feature could no longer be associated to a concept. We propose to interpret these subsidiary results as partially fitting with the predictions developed in the Sensory/Functional Theory (Warrington and Shallice, 1984). According to this model, perceptual features would be more salient for biological entities and critical to identify exemplars of living concepts. The SD patients' results were in agreement with the SFT account since the impact of perceptual attributes impairment appeared to be more pronounced for biological concepts. At the same time, the SD patients yielded a significant priming effect in the contextual condition only for biological concepts. We could thus consider that the state of semantic disequilibrium essentially affects knowledge about living entities. Since the ability to identify perceptual similarities between concepts was previously reported to be a core determinant to taxonomic relationships (Davidoff and Roberson, 2004) and since the two semantic relations systems were demonstrated to coexist and compete, we argue that these subsidiary results reinforce our hypothesis that breakdown of visuoperceptual attributes may disrupt similarity-based/taxonomic relations and give way to complementary-based/thematic ones. Nonetheless, even if these subsidiary analyses could partially fit with the SFT, this is not supported by the main results of the direct analysis contrasting living versus non living entities in the SD group. These last results therefore clearly contradict the core assumption of this model. In line with prior SD cases $(A N, C S, M A, A T, S L, I W$ : Lambon Ralph et al., 2003, 
1998; MF: Barbarotto et al., 1995; see also case review by Capitani et al., 2003), we demonstrated that impairment of visuoperceptual features in SD was not related to any global difference in accuracy between the two domains of knowledge (living versus non living entities), yet expected by the SFT predictions.

One limitation of our main line of interpretation concerns the difference in the nature of the prime and the target in the two attribute conditions. One could argue that visual condition involves a concept-feature link whereas contextual one refers to a concept-concept link. More generally, that criticism could be addressed against many experimental designs built in line with the SFT. Indeed, Tyler and Moss (1998) confronted in the same design perceptual features: "crocodile-green" versus functional ones "crocodile-river". Nonetheless, boundaries between a concept and a feature or an attribute remain unclear. We acknowledge that this may be a matter of debate. However, according to Wong and Gallate (2012), we assume that any feature - even if it is a single colour - can be seen as a unit of meaning and a concept in itself.

Our results suggesting that impairment of visuoperceptual features is a key deficit in SD could run counter to several reports demonstrating that semantic deficit in SD was not confined to concepts mainly depend upon visuoperceptual information, by means of explicit semantic tasks. Indeed, significant difference between the two domains of living and non living knowledge was rarely reported in SD patients (Lambon Ralph et al., 2003, 2007) and studies assessing the concreteness effect in SD highlighted an advantage of concrete/ high imageability words over abstract/ low imageability ones (Hoffman and Lambon Ralph, 2011; Hoffman et al., 2013; Jefferies et al., 2009). These findings were interpreted in light of the "hub and spoke" semantic framework (Rogers et al, 2004; Patterson et al, 2007; Lambon Ralph et al, 2010). This theory states that the anterior temporal lobe (ATL) is a critical region for a single convergence zone (a "hub") that brings together various modality-specific 
information from different sensory, motor and linguistic regions (the "spokes") into an amodal and coherent representation. Since SD is characterized by a bilateral atrophy and hypo metabolism maximal in the ATLs (Mummery et al., 2000; Nestor et al., 2006), the "hub and spoke" theory predicts the absence of any category-specific semantic deficit and any differential feature impairment after ATLs lesions. Our finding of a more severe impairment for visuoperceptual features could at first sight dismiss that strong prediction of the model. Nevertheless, such a more pronounced deficit for visuoperceptual attributes in SD patients was also highlighted, to some extent, by Hoffman et al. (2012). These authors showed no advantage for items rich in visual information in SD patients and interpreted it as a sign of a later additional breakdown of a modality-specific spoke region (specialized in the visual information processing), in line with a graded hub-and-spoke model of conceptual knowledge (i.e., a gradual convergence of information along the temporal lobes, with visual information in the posterior areas giving way to pan-modal representations in the ATLs). Two arguments could strengthen that conception. Firstly, visuoperceptual features, whenever tested through similarity-based/taxonomic relationships, were shown to activate more posterior areas rather than ATLs (Kalénine et al., 2009; Kotz et al., 2002). Secondly, the hypothesis of a later additional breakdown of a modality-specific spoke region specialized in the visual information processing seems to be in agreement with our results at follow up, since more patients exhibited an absence of priming in the visual condition one year later. That graded hub and spoke framework could be helpful to explain the visuoperceptual features impairment exhibited by the SD patients. Nonetheless, given that our study focused on the cognitive organization rather than on the neural basis of semantic knowledge in $\mathrm{SD}$, we could not accurately rely upon neuroanatomical accounts such as the hub and spoke model to interpret our core findings. Rather, the distinction proposed between thematic and taxonomic systems based on experimental psychology as a main factor organizing semantic knowledge at a 
cognitive level perfectly fits with our concerns i.e., with the fact SD patients generally displayed the opposite pattern of priming performances to controls.

To conclude, our priming paradigm comparing two semantic features (visuoperceptual versus contextual-functional attributes) revealed a reverse pattern of performances in the SD patients compared with controls. While controls exhibited priming in the visual condition but no significant priming effect in the contextual one, the SD patients showed exactly the opposite performances. We argue that these priming effects were not an artifact caused by cognitive slowing in the SD patients, and that they reflected semantic mechanisms rather than lexical processes. We interpreted the reverse pattern of performances in terms of a semantic knowledge disequilibrium and, more specifically, in terms of the differential recruitment of one of the two co-existing systems of semantic relationships. In controls, the similaritybased/taxonomic relationships automatically advantaged over complementary-based/thematic relationships, leading to a significant priming effect for visuoperceptual features without any priming for contextual-functional ones. In the SD patients, as perceptual features were impaired, the system of thematic relationships had to take over from the similaritybased/taxonomic one.

These results need to be set against the relative independence of SD patients in activities of daily living, despite their massive semantic deficit (Bier et al., 2013; Bier and Macoir, 2010). This relative independence is quite astonishing, given that in other degenerative diseases (including $\mathrm{AD}$ ), functional disorders hamper everyday life at a far earlier stage in the pathology. Regarding their functional abilities, SD patients have long been described with preserved object use despite their semantic memory breakdown (Buxbaum et al., 1997; Hodges et al., 2000; Lauro-Grotto et al., 1997). Hodges et al. (2000) and Bozeat et al. (2002) isolated several factors explaining the spared abilities to use objects: the residual conceptual knowledge, the conceptual familiarity, the personal familiarity and the visual 
object affordances (i.e., mechanisms that support object use directly from visual and/or tactile input). Nevertheless, Negri et al. (2007) argued that semantic knowledge is not a key factor in the success of object use. They proposed that these abilities depend upon motor knowledge, which may be represented separately from semantic knowledge in the brain. A possible alternative factor might be considered regarding the spared abilities to use objects and further investigations are needed to determine whether thematic relationships can operate as a relay system capable of managing knowledge about the use and function of concepts. Lin and Murphy (2001) related thematic categories to the concept developed by Barsalou (1991) of "goal-derived categories", where entities are brought together in a schema-like organization and share mutual constraints. We therefore need to determine whether knowledge of the context in which an object frequently appears, and its associations in space and time with other entities, is enough to deduce its scope of use.

\section{Acknowledgments}

We wish to thank all the participants and their families for their willingness to devote such effort to this study, and their endless patience. We are also grateful to Clotilde Minois for her help in collecting the data and to Elizabeth Portier for the English translation. 


\section{References}

Agniel, A., Joanette, Y., Doyon, B., \& Duchein, C. (1992). Protocole Montréal-Toulouse, Evaluation des Gnosies Visuelles et Auditives (PEGVA). Isbergues: L'Ortho Edition.

Abernethy, M., \& Coney, J. (1993). Associative priming in the hemispheres as a function of SOA. Neuropsychologia, 31, 1397-1409.

Balota, D. A., Watson, J. M., Duchek, J. M., \& Ferraro, F. R. (1999). Cross-modal semantic and homograph priming in healthy young, healthy old, and in Alzheimer's disease individuals. Journal of the International Neuropsychology Society: JINS, 5 (7), 626-640.

Barbarotto, R., Capitani, E., Spinnler, H., \& Trivelli, C. (1995). Slowly progressive semantic impairment with category specificity. Neurocase, 1, 107-119.

Barsalou, L. W. (1991). Deriving categories to achieve goals. In G. H. Bower (Ed.), The Psychology of Learning and Motivation (pp. 1-64). New York: Academic Press.

Benton, A. L., Sivan, A. B., Hamsher, K. de S., Varney, N. R., \& Spreen, O. (1994). Contributions to Neuropsychological Assessment. A Clinical Manual (2 $2^{\text {nd }}$ ed.). New York: Oxford University Press.

Bier, N., \& Macoir, J. (2010). How to make a spaghetti sauce with a dozen small things I cannot name: A review of the impact of semantic-memory deficits on everyday actions. Journal of Clinical and Experimental Neuropsychology, 32 (2), 201-211.

Bier, N., Bottari, C., Hudon, C., Joubert, S., Paquette, G., \& Macoir, J. (2013). The impact of semantic dementia on everyday actions: Evidence from an ecological study. Journal of the International Neuropsychological Society: JINS, 19 (2), 162-172.

Bouaffre, S., \& Faita-Ainseba, F. (2007). Hemispheric differences in the time-course of semantic priming processes: Evidence from event-related potentials (ERPs). Brain and Cognition, 63, 123-135.

Bozeat, S., Lambon Ralph, M. A., Patterson, K., Garrard, P., \& Hodges, J. R. (2000). Nonverbal semantic impairment in semantic dementia. Neuropsychologia, 38 (9), 1207-1215.

Bozeat, S., Lambon Ralph, M. A., Patterson, K., \& Hodges, J. R. (2002). When objects lose their meaning: What happens to their use? Cognitive, Affective \& Behavioral Neuroscience, 2, $236-251$.

Buxbaum, L. J., Schwartz, M. F., \& Carew, T. G. (1997). The role of semantic memory in object use. Cognitive Neuropsychology, 14, 219-254. 
Capitani, E., Laiacona, M., Mahon, B., \& Caramazza, A. (2003). What are the facts of semantic category-specific deficits? A critical review of the clinical evidence. Cognitive Neuropsychology, 20(3), 213-261.

Chan, D., Fox, N. C., Scahill, R. I., Crum, W. R., Whitwell, J. L., Leschziner, G., Rossor, A. M., Stevens, J. M., Cipolotti, L., \& Rossor, M. N. (2001). Patterns of temporal lobe atrophy in semantic dementia and Alzheimer's disease. Annals of Neurology, 49 (4), 433-442.

Chertkow, H., Bub, D., \& Seidenberg, M. (1989). Priming and semantic memory loss in Alzheimer's disease. Brain and Language, 36, 420-446.

Collins, A. M., \& Loftus, E. F. (1975). A spreading-activation theory of semantic processing. Psychological Review, 82 (6), 407-428.

Crawford, J. R., Garthwaite, P. H., \& Porter, S. (2010). Point and interval estimates of effect sizes for the case-controls design in neuropsychology: Rationale, methods, implementations, and proposed reporting standards. Cognitive Neuropsychology, 27 (3), 245-260.

Davidoff, J., \& Roberson, D. (2004). Preserved thematic and impaired taxonomic categorisation: A case study. Language and Cognitive Processes, 19, 137-174.

Davis, C., Heidler-Gary, J., Gottesman, R. F., Crinion, J., Newhart, M., Moghekar, A., Soloman, D., Rigamonti, D, Cloutman, L., \& Hillis, A. E. (2010). Action versus animal naming fluency in subcortical dementia, frontal demantias, and Alzheimer's disease. Neurocase, 16(3), 259-266.

Denney, D. R. (1975). Developmental changes in concept utilization among normal and retarded children. Developmental Psychology, 11, 359-368.

De Zubicaray, G. I., Hansen, S., \& McMahon, K.L. (2013). Differential processing of thematic and categorical conceptual relations in spoken word production. Journal of Experimental Psychology: General, 142 (1), 131-142.

Estes, Z., \& Jones, L. L. (2009). Integrative priming occurs rapidly and uncontrollably during lexical processing. Journal of Experimental Psychology. General, 138, 112-130.

Giffard, B., Desgranges, B., Nore-Mary, F., Lalevée, C., de la Sayette, V., Pasquier, F., \& Eustache, F. (2001). The nature of semantic memory deficits in Alzheimer's disease: New insights from hyperpriming effects. Brain, 124 (8), 1522-1532.

Giffard, B., Desgranges, B., Nore-Mary, F., Lalevée, C., Beaunieux, H., de la Sayette, V., Pasquier, F., \& Eustache, F. (2002). The dynamic time course of semantic memory 
impairment in Alzheimer's disease: Clues from hyperpriming and hypopriming effects. Brain, 125 (9), 2044-2057.

Giffard, B., Desgranges, B., Kerrouche, N., Piolino, P., \& Eustache, F. (2003). The hyperpriming phenomenon in normal aging: A consequence of cognitive slowing? Neuropsychology, 17 (4), 594-601.

Goodglass, H., \& Kaplan, E. (1972). The Assessment of Aphasia and Related Disorders. Philadelphia: Lea and Febiger.

Hodges, J. R., Patterson, K., Oxbury, S., \& Funnell, E. (1992). Semantic dementia. Progressive fluent aphasia with temporal lobe atrophy. Brain, 115 (6), 1783-1806.

Hodges, J. R., Bozeat, S., Lambon Ralph, M. A., Patterson, K., \& Spatt, J. (2000). The role of conceptual knowledge in object use. Evidence from semantic dementia. Brain, 123, 19131925.

Hoffman, P., \& Lambon Ralph, M. A. (2011). Reverse concreteness effects are not a typical feature of semantic dementia: Evidence for the hub-and-spoke model of conceptual representation. Cerebral Cortex, 21, 2103-2112.

Hoffman, P., Jones, R. W., \& Lambon Ralph, M. A. (2012). The degraded concept representation system in semantic dementia: Damage to pan-modal hub, then visual spoke. Brain, 135, 3770-3780.

Hoffman, P., Jones, R. W., \& Lambon Ralph, M. A. (2013). Be concrete to be comprehended: Consistent imageability effects in semantic dementia for nouns, verbs, synonyms and associates. Cortex, 49, 1206-1218.

Howard, D., \& Patterson, K. (1992). The Pyramids and Palm Trees Test: A test for semantic access from words and pictures. Bury St Edmunds: Thames Valley Test Company.

Jefferies, E., Lambon Ralph, M. A. (2006). Semantic impairment in stroke aphasia versus semantic dementia: a case-series comparison. Brain, 129, 2132-2147.

Jefferies, E., Patterson, K., Jones, R. W., Lambon Ralph, M. A. (2009). Comprehension of concrete and abstract words in semantic dementia. Neuropsychology, 23, 492-499.

Jones, L. L., \& Golonka, S. (2012). Different influences on lexical priming for integrative, thematic, and taxonomic relations. Frontiers in Human Neuroscience, 6, 205: 1-17.

Kalénine, S., Peyrin, C., Pichat, C., Segebarth, C., Bonthoux, F., \& Baciu, M. (2009). The sensory-motor specificity of taxonomic and thematic conceptual relations: A behavioral and 
fMRI study. Neuroimage, 44 (3), 1152-1162.

Kotz, S. A., Cappa, S. F., von Cramon, D. Y., \& Friederici, A. D. (2002). Modulation of the lexical-semantic network by auditory semantic priming: An event-related functional MRI study. Neuroimage, 17, 1761-1772.

Laisney, M., Giffard, B., Belliard, S., de La Sayette, V., Desgranges, B., \& Eustache, F. (2011). When the zebra loses its stripes: Semantic priming in early Alzheimer's disease and semantic dementia. Cortex. 47 (1), 35-46.

Lambon Ralph, M. A., Howard, D., Nightingale, G., \& Ellis, A. W. (1998). Are living and non living category-specific deficits causally linked to impaired perceptual or associative knowledge? Evidence from a category-specific double dissociation. Neurocase, 4, 311-338.

Lambon Ralph, M. A., Patterson, K., Garrard, P., \& Hodges, J. R. (2003). Semantic dementia with category specificity: A comparative case-series study. Cognitive Neuropsychology, 20 (3), 307-326.

Lambon Ralph, M. A., Lowe, C., \& Rogers, T. T. (2007). Neural basis of category-specific semantic deficits for living things: Evidence from semantic dementia, HSVE and a neural network model. Brain, 130, 1127-1137.

Lambon Ralph, M. A., Sage, K., Jones, R., \& Mayberry, E. (2010). Coherent concepts are computed in the anterior temporal lobes. Proceedings of the National Academy of Sciences of the United States of America, 107, 2717-2722.

Lauro-Grotto, R., Piccini, C., \& Shallice, T. (1997). Modality-specific operations in semantic dementia. Cortex, 33, 593-622.

Lin, E. L., \& Murphy, G. L. (2001). Thematic relations in adults' concepts. Journal of Experimental Psychology, 130 (1), 3-28.

Lucas, M. (2000). Semantic priming without association: A meta-analytic review. Psychonomic Bulletin \& Review, 7, 618-630.

Luzzi, S., Snowden, J. S., Neary, D., Coccia, M., Provinciali, L., \& Lambon Ralph, M. A. (2007). Distinct patterns of olfactory impairment in Alzheimer's disease, semantic dementia, frontotemporal dementia, and corticobasal degeneration. Neuropsychologia, 45 (8), 18231831.

Maguire, M. J., Brier, M. R., \& Ferree, T. C. (2010). EEG theta and alpha responses reveal qualitative differences in processing taxonomic versus thematic semantic relationships. Brain 
and Language, 114, 16-25.

Mattis, S. (1976). Mental status examination for organic mental syndrome in the elderly patients. In L. Bellak, \& T. Karasu (Eds.), Geriatrics Psychiatry: A Handbook for Psychiatrists and Primary Care Physicians (pp. 77-121). New York: Grune and Stratton.

Medin, D., \& Ortony, A. (1989) Psychological essentialism. In S. Vosniadou, \& A. Ortony (Eds.), Similarity and Analogical Reasoning (pp. 179-195). New York: Cambridge University Press.

Merck, C., Charnallet, A., Auriacombe, S., Belliard, S., Hahn-Barma, V., Kremin, H., Lemesle, B., Mahieux, F., Moreaud, O., Perrier Palisson, D., Roussel, M., Sellal, F., \& Siegwart, H. (2011). La batterie d'évaluation des connaissances sémantiques du GRECO (BECS-GRECO) : validation et données normatives. [The GRECO neuropsychological semantic battery (BECS GRECO): Validation and normative data]. Revue de Neuropsychologie, 3 (4), 235-255.

Meteyard, L., \& Patterson, K. (2009). The relation between content and structure in language production: An analysis of speech errors in semantic dementia. Brain and Language, 110 (3), 121-134.

Mirman, D., \& Grazanio, K. M. (2012a). Individual differences in the strength of taxonomic versus thematic relations. Journal of Experimental Psychology: General, 141 (4), 601-609.

Mirman, D., \& Grazanio, K. M. (2012b). Damage to temporo-parietal cortex decreases incidental activation of thematic relations during spoken word comprehension. Neuropsychologia, 50, 1990-1997.

Moreaud, O., Belliard, S., Snowden, J., Auriacombe, S., Basaglia-Pappas, S., Bernard, F., Bon, L., Boutantin, J., Boutoleau-Bretonnière, C., Charnallet, A., Coutant, E., David, D., Deramecourt, V., Gaestel, Y., Garnier, S., Guichart, E., Hahn-Barma, V., Lebail, B., LebrunGivois, C., Lamy, E., Le Carret, N., Lemesle, B., Memin, A., Parienté, J., Pasquier, F., Renou, P., Rouaud, O., Sarazin, M., Thomas-Antérion, C., Vercelletto, M., \& Virat-Brassaud, M. E. (2008). Démence sémantique: Réflexions d'un groupe de travail pour des critères de diagnostic en français et la constitution d'une cohorte de patients. [Semantic dementia: Reflexions of a French working group for diagnostic criteria and constitution of a patient cohort]. Revue Neurologique, 164 (4), 343-353.

Moss, H. E., Tyler, L. K., Patterson, K., \& Hodges, J. R. (1995a). Exploring the loss of semantic memory in semantic dementia: Evidence from a primed monitoring study. 
Neuropsychology, 9 (1), 16-26.

Moss, H. E., Ostrin, R. K., Tyler, L. K., \& Marslen-Wilson, W. D. (1995b). Accessing different types of lexical semantic information: Evidence from priming. Journal of Experimental Psychology: Learning, Memory, and Cognition, 21, 863-883.

Mummery, C. J., Patterson, K., Price, C. J., Ashburner, J., Frackowiak, R. S. J., \& Hodges, J. R. (2000). A voxel-based morphometry study of semantic dementia: Relationship between temporal lobe atrophy and semantic memory. Annals of Neurology, 47, 36-45.

Nakamura, H., Nakanishi, M., Hamanaka, T., Nakaaki, S., \& Yoshida, S. (2000). Semantic priming in patients with Alzheimer and semantic dementia. Cortex, 36 (2), 151-162.

Neary, D., Snowden, J. S., Gustafson, L., Passant, U., Stuss, D., Black, S., Freedman, M., Kertesz, A., Robert, P. H., Albert, M., Boone, K., Miller, B. L., Cummings, J., \& Benson, D. (1998). F. Frontotemporal lobar degeneration: A consensus on clinical diagnostic criteria. Neurology, 51 (6), 1546-1554.

Nebes, R. D., Brady, C. B., \& Huff, F. J. (1989). Automatic and attentional mechanisms of semantic priming in Alzheimer's disease. Journal of Clinical and Experimental Neuropsychology, 11, 219-230.

Neely, J. H. (1977). Semantic priming and retrieval from lexical memory: Roles of inhibitionless spreading activation and limited-capacity attention. Journal of Experimental Psychology: General, 106 (3), 226-254.

Negri, G. A., Lunardelli, A., Reverberi, C., Gigli, G. L., \& Rumiati, R. I. (2007). Degraded semantic knowledge and accurate object use. Cortex, 43, 376-388.

Nestor, P. J., Fryer, T. D., \& Hodges, J. R. (2006). Declarative memory impairments in Alzheimer's disease and semantic dementia. Neuroimage, 30, 1010-1020.

New, B., Pallier, C., Brysbaert, M., \& Ferrand, L. (2004). Lexique 2: A new French lexical database. Behavior Research Methods, Instruments, \& Computers, 36 (3), 516-524.

Nguen, S. P., \& Murphy, G. L. (2003). An apple is more than just a fruit: Cross-classification in children's concepts. Child Development, 74 (6), 1783-1806.

Ober, B. A. (2002). RT and non-RT methodology for semantic priming research with Alzheimer's disease patients: A critical review. Journal of Clinical and Experimental Neuropsychology, 24 (7), 883-911.

Osterrieth, P. A. (1944). Le test de copie d'une figure complexe: Contribution à l'étude de la 
perception et de la mémoire [The test of copying a complex figure: A contribution to the study of perception and memory]. Archives de Psychologie, 30, 286-356.

Patterson, K., Nestor, P. J., \& Rogers, T. T. (2007). Where do you know what you know? The representation of semantic knowledge in the human brain. Nature Reviews. Neuroscience, 8 (12), 976-987.

Perri, R., Zannino, G. D., Caltagirone, C., \& Carlesimo, G. A. (2011). Semantic priming for coordinate distant concepts in Alzheimer's disease patients. Neuropsychologia, 49 (5), 839847.

Raven, J., Raven, J. C., \& Court, J. H. (1998). Raven Manual: Standard Progressive Matrices. Oxford: Oxford Psychologists Press.

Rogers, T. T., Lambon Ralph, M. A., Garrard, P., Bozeat, S., McClelland, J. L., Hodges, J. R., \& Patterson, K. (2004). Structure and deterioration of semantic memory: A neuropsychological and computational investigation. Psychological Review, 111(1), 205-235.

Rogers, S. L., \& Friedman, R. B. (2008). The underlying mechanisms of semantic memory loss in Alzheimer's disease and semantic dementia. Neuropsychologia, 46 (1), 12-21.

Sachs, O., Weis, S., Krings, T., Huber, W., \& Kircher, T. (2008a). Categorical and thematic knowledge representation in the brain: Neural correlates of taxonomic and thematic conceptual relations. Neuropsychologia, 46 (2), 409-418.

Sachs, O., Weis, S., Zellagui, N., Huber, W., Zvyagintsev, M., Mathiak, K., \& Kircher, T. (2008b). Automatic processing of semantic relations in fMRI: Neural activation during semantic priming of taxonomic and thematic categories. Brain Research, 1218, 194-205.

Sachs, O., Weis, S., Zellagui, N., Sass, K., Huber, W., Zvyagintsev, M., Mathiak, K., \& Kircher, T. (2011). How different types of conceptual relations modulate brain activation during semantic priming. Journal of Cognitive Neuroscience, 23, 1263-1273.

Sass, K., Sachs, O., Krach, S., \& Kircher, T. (2009). Taxonomic and thematic categories: Neural correlates of categorization in an auditory-to-visual priming task using fMRI. Brain Research, 1270, 78-87.

Schwartz, M. F., Kimberg, D. Y., Walker, G. M., Brecher, A., Faseyitan, O. K., Dell, G. S., Mirman, D., \& Coslett, H. B. (2011). Neuroanatomical dissociation for taxonomic and thematic knowledge in the human brain. Proceedings of the National Academy of Sciences of the United States of America, 108 (20), 8520-8524. 
Silveri, M. C., Perri, R., \& Cappa, A. (2003). Grammatical class effects in brain-damaged patients: Functional locus of noun and verb deficit. Brain and Language, 85, 49-66.

Simmons, S., \& Estes, Z. (2008). Individual differences in the perception of similarity and difference. Cognition, 108 (3), 781-795.

Snowden, J. S., Goulding, P. J., \& Neary D. (1989). Semantic dementia: A form of circumscribed cerebral atrophy. Behavioural Neurology, 2, 167-182.

Snowden, J. S., Thompson, J. C., \& Neary, D. (2004). Knowledge of famous faces and names in semantic dementia. Brain, 127(4), 860-872.

Stefaniak, N., Meulemans, T., \& Willems, S. (2010). Semantic hyperpriming in normal aging: A consequence of instructions? Neuropsychology, Development and Cognition. Section B: Aging, Neuropsychology and Cognition, 17 (5), 615-632.

Tyler, L. K., \& Moss, H. E. (1997). Functional properties of concepts: Studies of normal and brain-damaged patients. Cognitive Neuropsychology, 14 (4), 511-545.

Tyler, L. K., \& Moss, H. E. (1998). Going, going, gone...? Implicit and explicit tests of conceptual knowledge in a longitudinal study of semantic dementia. Neuropsychologia, 36 (12), 1313-1323.

Violon, A., \& Wijns, C. (1984). Le test de la Ruche. Test de perception et d'apprentissage progressif en mémoire visuelle. Braine le Château: Editions l'Application des techniques modernes SPRL.

Warrington, E.K., \& Shallice, T. (1984). Category specific semantic impairments. Brain, 107 (3), 829-854.

Wechsler, D. (1981). Wechsler Adult Intelligence Scale Revised Manual. New York: The Psychological Corporation.

Wong, C., \& Gallate, J. (2012). The function of the anterior temporal lobe: A review of the empirical evidence. Brain Research, 1449, 94-116. 


\section{Tables and Figure}

Table 1 SD patients' and controls' demographic and clinical features

\begin{tabular}{|c|c|c|c|c|c|c|c|c|c|c|c|}
\hline & \multicolumn{2}{|l|}{ Controls } & \multicolumn{9}{|c|}{ SD patients } \\
\hline & $\begin{array}{l}\text { Mean } \\
\text { (standard deviation) }\end{array}$ & Range & SD1 & $\mathrm{SD} 2$ & SD3 & SD4 & SD5 & SD6 & SD7 & SD8 & $\begin{array}{l}\text { Mean } \\
\text { (Standard deviation) }\end{array}$ \\
\hline Sex (Female; Male) & $20 \mathrm{~F} ; 11 \mathrm{M}$ & & $\mathrm{F}$ & $\mathrm{F}$ & $\mathrm{M}$ & $\mathrm{F}$ & $\mathrm{M}$ & $\mathrm{F}$ & $\mathrm{F}$ & $\mathrm{F}$ & $6 \mathrm{~F} ; 2 \mathrm{M}$ \\
\hline Age (years) & $62.8(4.8)$ & $56-72$ & 64 & 62 & 69 & 58 & 66 & 63 & 75 & 64 & $65.1(5.1)$ \\
\hline $\begin{array}{l}\text { Handedness } \\
(\mathrm{L}=\text { left } ; \mathrm{R}=\text { right })\end{array}$ & $1 \mathrm{~L} ; 30 \mathrm{R}$ & & $\mathrm{R}$ & $\mathrm{R}$ & $\mathrm{L}$ & $\mathrm{R}$ & $\mathrm{R}$ & $\mathrm{L}$ & $\mathrm{R}$ & $\mathrm{R}$ & $2 \mathrm{~L} ; 6 \mathrm{R}$ \\
\hline Education (years) & $12.1(4.1)$ & $7-21$ & 9 & 9 & 14 & 12 & 12 & 19 & 9 & 8 & $11.5(3.7)$ \\
\hline Disease duration (months) & & & 27 & 32 & 11 & 17 & 3 & 16 & 13 & 1 & $15(10.7)$ \\
\hline $\begin{array}{l}\text { Side of atrophy } \\
\text { ( } L=\text { left; } B=\text { bilateral; } R= \\
\text { right) }\end{array}$ & & & B & $\mathrm{B}$ & B & $\mathrm{L}$ & B & $\mathrm{R}$ & $\mathrm{L}$ & $\mathrm{L}$ & (3 L; 4B; 1R) \\
\hline
\end{tabular}




\begin{tabular}{|c|c|c|c|c|c|c|c|c|c|c|c|c|c|c|}
\hline \multirow[t]{3}{*}{ Tests } & \multirow[b]{3}{*}{$\begin{array}{l}\text { Maximum } \\
\text { score }\end{array}$} & \multirow{3}{*}{$\begin{array}{l}\text { Controls } \\
\text { Mean } \\
\text { (standard } \\
\text { deviation) } \\
\text { or cut-off } \\
\text { at 5\% }\end{array}$} & \multicolumn{12}{|c|}{ SD patients } \\
\hline & & & \multicolumn{8}{|c|}{ Baseline } & \multicolumn{4}{|c|}{ Follow up } \\
\hline & & & SD1 & SD2 & SD3 & SD4 & SD5 & SD6 & SD7 & SD8 & SD2 & SD4 & SD5 & SD6 \\
\hline $\begin{array}{l}\text { General cognitive } \\
\text { functioning (DRS score) }\end{array}$ & 144 & $141(2.2)$ & 103 & 107 & 111 & 117 & 121 & 128 & 132 & 85 & 97 & 116 & 122 & 122 \\
\hline RCPM & 36 & 15 & 33 & 35 & 33 & 34 & 36 & 33 & 26 & 33 & 34 & 31 & 32 & 33 \\
\hline $\begin{array}{l}\text { Nonverbal episodic } \\
\text { memory } \\
\text { "La Ruche" visuospatial } \\
\text { learning task }\end{array}$ & & & & & & & & & & & & & & \\
\hline $\begin{array}{l}\text { Immediate free recall - sum } \\
\text { of the } 5 \text { trials }\end{array}$ & 50 & 16 & - & - & 38 & 47 & 32 & 36 & 40 & 39 & - & 45 & 47 & 45 \\
\hline $\begin{array}{l}\text { Immediate forced-choice } \\
\text { recognition }\end{array}$ & 10 & 7 & - & - & 10 & 10 & 10 & 10 & 8 & 10 & - & 9 & 10 & 10 \\
\hline Delayed free recall & 10 & 4 & - & - & 10 & 10 & 8 & 10 & 9 & 10 & - & 10 & 9 & 8 \\
\hline Delayed recall of ROCF - & 36 & 5 & 21 & 3 & 14 & 23 & 25.5 & - & 18.5 & 15.5 & 2 & - & 25.5 & - \\
\hline
\end{tabular}


Form A

Working memory

\begin{tabular}{|c|c|c|c|c|c|c|c|c|c|c|c|c|c|}
\hline $\begin{array}{l}\text { Digit Span Forward } \\
\text { (WAIS-R) }\end{array}$ & 9 & 4 & 6 & 5 & 6 & 6 & 4 & 7 & 6 & 6 & 6 & 6 & 4 \\
\hline $\begin{array}{l}\text { Digit Span Backward } \\
\text { (WAIS-R) }\end{array}$ & 8 & 3 & 4 & 6 & 5 & 4 & 4 & 5 & 5 & 2 & 4 & 6 & 4 \\
\hline
\end{tabular}

Language and semantic

memory

Irregular word reading test 18

Regular word reading test 18

Single word repetition $\quad 10$

17

subtest (BDAE)

BECS GRECO picture-

naming task

\section{BECS GRECO Verbal}

40

semantic matching task

BECS GRECO Visual

40

semantic matching task

BECS GRECO - sum of the

120

$\begin{array}{lllllllllllll}17 & 14 & 16 & 12 & 18 & 11 & 17 & 17 & 14 & 14 & 17 & 15 & 17 \\ 17 & 18 & 18 & 17 & 18 & 18 & 18 & 18 & 17 & 18 & 18 & 18 & 18 \\ 9 & 10 & 10 & 9.5 & 10 & 10 & 10 & 10 & 10 & 10 & 10 & 10 & 10\end{array}$

3 tasks

39.

(1)

39.9

2

(0.5)

39.9

26

(0.3)

118.9

$\begin{array}{lll}0 & 2 & 3\end{array}$

$10 \quad 14$

13

211

$\begin{array}{llll}1 & 5 & 10 & 6\end{array}$

Level of the overall 
semantic impairment

(Mild : 1; Moderate: 2;

Severe: 3)

Visuoperceptual abilities

Benton Facial Recognition

54

38

$50 \quad 54$

49

44

49

44

30

$36 \quad 36$

35

subtest

Copy of ROCF -Form A 36

29 
Table 3 SD patients' and controls' mean accuracy (expressed as percentage of correct responses) and mean RTs in milliseconds (standard deviations: SD) for both semantically related and unrelated word pairs in the two attribute conditions (visual and contextual)

\begin{tabular}{|c|c|c|c|c|c|c|c|}
\hline & & \multicolumn{3}{|l|}{ Visual } & \multicolumn{3}{|l|}{ Contextual } \\
\hline & & Related condition & Unrelated condition & & Related condition & Unrelated condition & \\
\hline & & Mean (SD) & Mean (SD) & $\mathrm{p}$ & Mean (SD) & Mean (SD) & $\mathrm{p}$ \\
\hline Accuracy & SD patients & $89.8(13.3)$ & $90.9(11.9)$ & 0.685 & $93.2(9.1)$ & $92(9.9)$ & 0.649 \\
\hline RTs & Controls & $632(88.8)$ & $662.9(101.7)$ & $<0.001$ & $618.6(93.2)$ & $626.8(78.7)$ & 0.262 \\
\hline
\end{tabular}

$p: \mathrm{p}$ values for the paired-samples $t$-tests. 
Figure 1 Priming effect expressed as a percentage ([mean RT for unrelated condition - mean RT for related condition] / mean RT for unrelated condition *100) in the visual and contextual conditions for the SD patients and controls

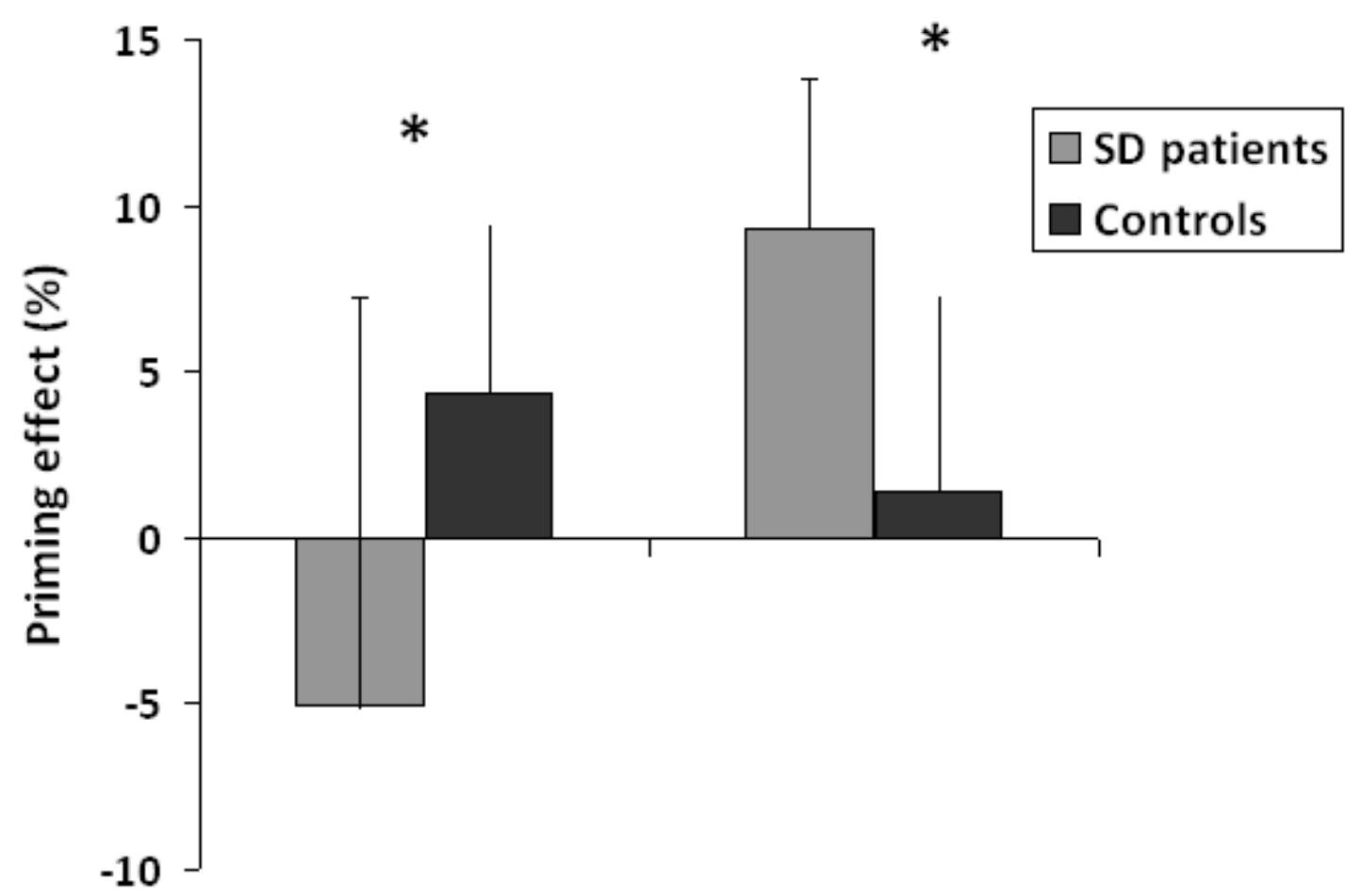

Visual Contextual

$*$ significant between-group comparisons at $p<.05$. Error bars represent standard error of the mean. 